\title{
Estimation of Surface Winds From Upward Looking Acoustic Doppler Current Profilers
}

\author{
J. Brown', E.D. Barton, A. Trasviña ${ }^{2}$ and H.S. Velez \\ School of Ocean Sciences. University of Wales, Bangor \\ Menai Bridge. Gwynedd, Wales
}

P.M. KOSRO AND R.L. SMITH

College of Oceanography, Oregon State University, Corvallis

\begin{abstract}
Three upward looking acoustic Doppler current profilers (ADCP) were deployed beneath meteorologicalbuoys in the Gulf of Tehuantepec. Mexico. during winter 1988-1989. Hourly averaged wind speed data from the buoys and from ship when in the vicinity were compared with surface acoustic backscatter intensity recorded at the ADCPs. The backscatter was found to be a significant predictor of wind speeds from both buoy and ship. the latter when within $50 \mathrm{~km}$ of the mooring site. There was no apparent saturation of the backscattersignal at the maximum wind speeds $\left(<15 \mathrm{~m} \mathrm{~s}^{-1}\right)$. The results cast doubt on the ability of near-surface Doppler directional information to provide reliable estimates of wind direction.
\end{abstract}

\section{INTRODUCTION}

Moored acoustic Doppler current profilers (ADCPs) provide a powerful technique by which to routinely measure the velocity fields in a diversity of marine situations [e.g., Schott and Johns, 1987; Derecki and Quinn, 1987; Johns, 1988; Schott and Leaman, 1991]. Despite this versatility, when the air-water interface falls within range of the instrument, the near-surface information is of limited value. There exists a surface "shadow" zone of vertical extent

$$
\mathrm{D}(1-\cos \phi)
$$

where $\mathrm{D}=$ depth of the ADCP transducer and $\phi=$ angle of the transmitted pulse relative to the vertical. Energy returning to the transducer from the strong sea surface echo coincides with the signal from the scatterers within the shadow zone and swamps suppression of the sidelobe against the main beam [RD Instruments, 1989]. Consequently, within this zone derived water velocities are generally discarded. Schott [1989], employing the well-established dependence of surface backscatter energy on wind speed [e.g., Apel, 1987; Urick, 1975], has indicated that useful information can be extracted from the near-surface ADCP signals. Such data, recorded at two ADCP moorings deployed in the Gulf of Lions, were found to be significantly correlated with 12 hourly averages of ship board wind speed recorded within a radius of $100 \mathrm{~km}$. Additionally, directional information obtained from near-surface ADCP velocity measurements in the shadow zone was closely related to wind direction over portions of the time series.

In this note we consider the application of this technique to data collected in the vicinity of three meteorological buoy/ADCP mooring pairs deployed in the Gulf of Tehuantepec, Mexico (Figure 1). This aspect of the study can be considered analogous to that of Schott [1989] in that both regions experience strong

\footnotetext{
'Now at M.A.F.F., Fisheries Laboratory, Lowestoft, Suffolk, England.

${ }^{2}$ Now at Centro de Investigacion Cientifica y Educacion Superior de Ensenada, Ensenada, British Colombia, Mexico.
}

Copyright 1992 by the American Geophysical Union. transient winds of limited fetch blowing from the land. The in situ meteorological buoy records, absent in the Gulf of Lions, were curtailed by buoy and instrument failure and the ADCP records offered the potential to construct the full wind velocity time series. While it proved possible to determine accurately the wind speed from the ADCP, on time scales of the order of 1 hour, the ability to determine directional information must be open to question.

\section{THE OBSERVATIONS}

During December 1988 to February 1989 a study of the response of the Gulf of Tehuantepec, situated off the southwest Pacific coast of Mexico (Figure 1), to intermittent wind events, known locally as "Northers" was carried out [Trasvina, 1991; E.D. Barton et al., Supersquirt: The Dynamics of the Gulf of Tehuantepec, Mexico, submitted to Oceanography, 1992]. The winds, first detailed by Hurd [1929], predominantly occur during October to March when incursions of high-pressure polar air into the Gulf of Mexico drive a series of fierce wind jets through the Chivela Pass, a break in the northwest-southeast mountain range of Central America, many hundreds of kilometers into the lower pressure regime over the Pacific. The typical duration of a wind pulse is 2-5 days with velocities of $10-30 \mathrm{~m} \mathrm{~s}^{-1}$. In the central Gulf, strong surface circulations, of order $1.2 \mathrm{~m} \mathrm{~s}^{-1}$, , and intense cooling, by as much as $15^{\circ} \mathrm{C}$ with respect to the surrounding Pacific, are induced [Trasvina, 1991; Roden, 19611.

A major component of the work was a comprehensive hydrographic survey of the Gulf from January 15 to February 9 undertaken aboard the RV Wecoma, equipped with a full meteorological suite. To assist in defining the lateral extent of the wind jet and determine the shear across it, three meteorological buoys, recording wind speed and direction approximately $1.3 \mathrm{~m}$ above the nominal sea surface, were moored in $4000 \mathrm{~m}$ of water perpendicular to the axis of the wind (positions $14^{\circ} 32.1^{\prime} \mathrm{N}$ $96^{\circ} 10.8^{\circ} \mathrm{W}(\mathrm{M} 1), 14^{\circ} 15.8^{\circ} \mathrm{N} 95^{\circ} 15.7^{\circ} \mathrm{W}(\mathrm{M} 2)$, and $13^{\circ} 44.5^{\circ} \mathrm{N}$ $94^{\circ} 22.3^{\prime} \mathrm{W}$ (M3)) (Figure 1). M1 was lost; M2 collected wind speed and direction for 74 hours, but sank during the strong wind event; M3 collected wind speed for 260 hours, but the direction sensor malfunctioned at the start of the experiment.

Situated below each buoy on a separate mooring was an upward looking 307.2-kHz ADCP configured for a 30" acoustic beam angle, RDI serial numbers 197 (M1), 201 (M2), and 209 (M3). 

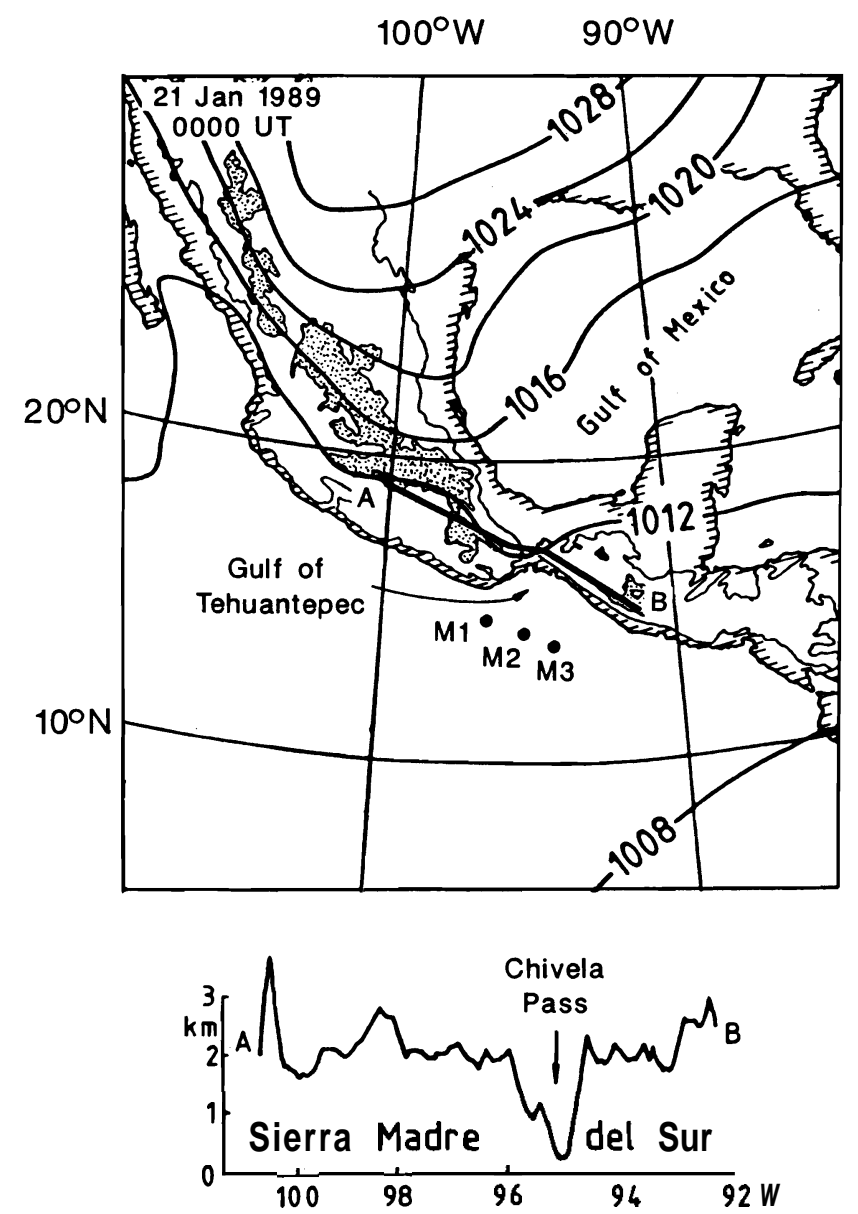

Fig. 1. Pressure regime that generated the Norther of January 21-23, 1989. and the relative positions of the meteorological buoy/ADCP mooring pairs (M1, M2, and M3). Section (AB) illustrates the relief along the Sierra Madre del Sur.

The respective depths of the instruments were $135( \pm 1), 124( \pm 2)$, and 147 (f 1) m, as determined at Aanderaa RCM4 current meters located $12 \mathrm{~m}$ beneath each ADCP. At the depth of the instruments, isolated from the vigorous wind-generated surface flows (maximum $120 \mathrm{~cm} \mathrm{~s}^{-1}$ ) by the strong thermocline $(\mathrm{AT} \approx$ $8^{\circ} \mathrm{C}$ ), ambient flows were of the order $10-30 \mathrm{~cm} \mathbf{s}^{-1}$, inducing minimal mooring motion. The ADCP parameters used were a nominal 4-m bin length, 135 pings per ensemble, and an ensemble time average of 300 seconds.

The onset of northers is often dramatic, as observed at M2 on February 21, when wind speed increased by $10 \mathrm{~m} \mathrm{~s}^{-1}$ in 90 mins (Figure 2b). Additionally, considerable spatial variability existed in the wind speed field over the Gulf. For example, at the peak of the event lasting from January 21 to 24 the Wecoma was forced to shelter at the head of the Gulf, resulting in distinct differences in ship board speed (Figure 2a) from that measured at M3 (Figure 2d). The wind jet fans out over the Gulf as it exits the Chivela Pass, so that mean directions recorded within $50 \mathrm{~km}$ of $\mathbf{M} 1$ in the west and M3 in the east differed by $69^{\circ}$ (Table 1). It was therefore necessary that intercomparisons were made between instruments in close proximity. For the purposes of this work, meteorological buoy and ADCP pairings were sufficiently close $(<2 \mathrm{~km})$ to regard them as a single mooring, thereby enabling direct comparisons of hourly averaged data. When buoy data were unavailable, ship board wind data within a $50-\mathrm{km}$ or even $20-\mathrm{km}$ radius were examined.
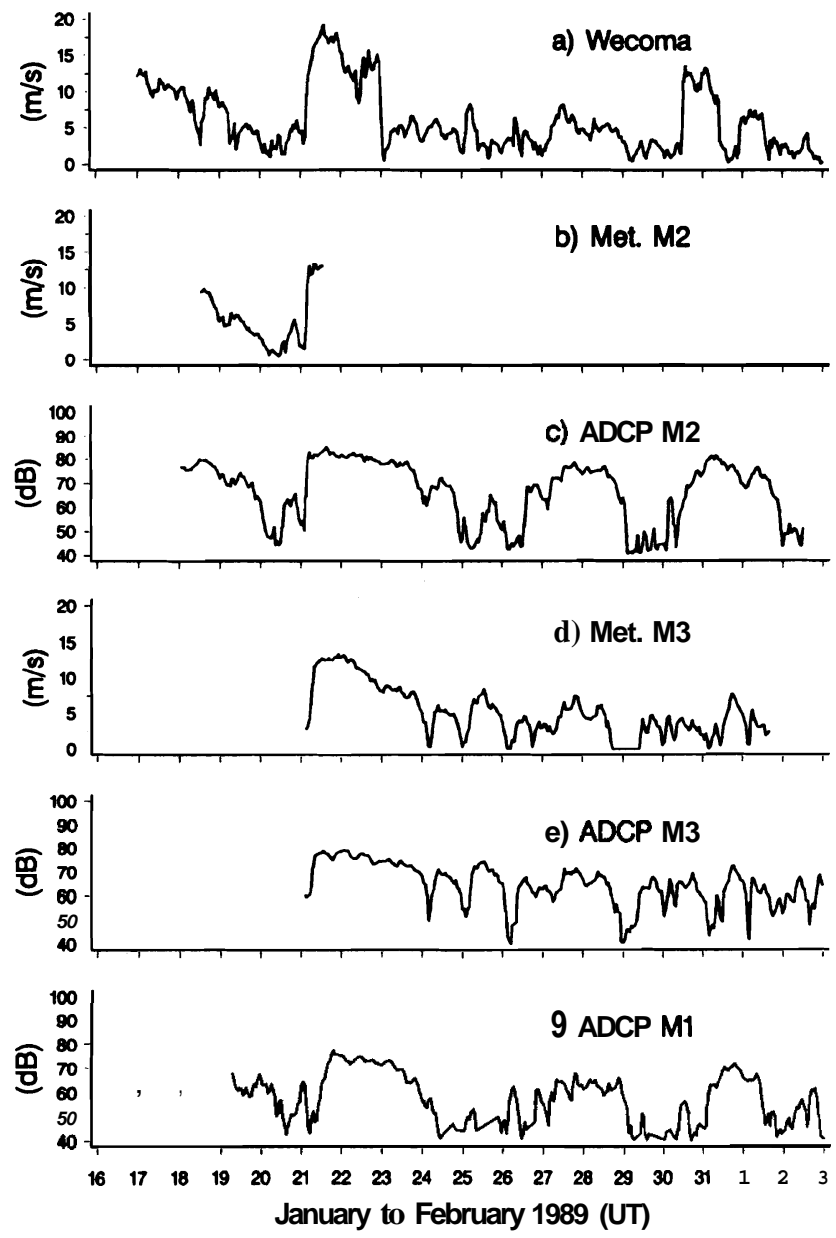

Fig. 2. lime series of ( $a$ ) ship board wind speed from the Wecoma, (b) meteorological buoy $\mathrm{M} 2$ wind speed. (c) near-surface $E S(\mathrm{~dB})$ signal at M2, (d) meteorological buoy M3 wind speed, (e) near-surface $E S(\mathrm{~dB})$ signal at $M 3$, and $(f)$ near-surface $E S(\mathrm{~dB})$ signal at $\mathrm{M} 1$.

\section{WIND SPEED ESTIMATES}

The ADCP backscatter energy (E) may be related to near-surface wind speed $(\mathrm{U})$ by a power law dependence of the form $\mathrm{E}-U^{b}$ [Schott, 1989], analogous to that typically applied in satellite scatterometry [e.g., Jones et $\mathbf{a l}$., 1982]. Urick [1975] also provides a discussion of the variation in scattering strength from beneath the sea surface with angle, frequency, and wind strength, although the sound sources utilized were primarily nondirectional (i.e., explosives).

The echo intensity, or strength $(E S(\mathrm{~dB}))$ of the backscattered signal, within each bin as measured by the ADCP is a byproduct of the automatic gain control (AGC) circuitry $[R D$ Instruments. 1989]. When calibration data are not available, RD Instruments suggests using a linear scale factor, 0.46 counts/dB at $22^{\circ} \mathrm{C}$, to convert AGC counts to ES(dB). Each of the ADCPs used in this experiment, however, had previously been calibrated by $\mathrm{RD}$ Instruments to determine the variation in this scale factor with the ambient temperature of the electronics (typically, $0.34 \%$ per ${ }^{\circ} \mathrm{C}$ [Heywood et al., 1991]) and with signal strength. These data were fit to an expression of the form

$$
E S(\mathrm{~dB})=c_{0}(T)+\mathrm{c},(T){ }^{*} \mathrm{AGC}+c_{2}(T){ }^{*} \mathrm{AGC}
$$

where the coefficients $c_{0}, \mathrm{c}$, and $c_{2}$ were allowed to vary quadratically with temperature [see Flagg and Smith. 1989]. 
TABLE I. Mean Direction of Near-Surface ADCP Data and Ship Winds Within $50 \mathrm{~km}$ of the Moorings

$\begin{array}{lll}\text { Mooring MI } & \text { Mooring M2 } & \text { Mooring M3 } \\ \text { 0700 UT Jan 19 to } & \text { 0100 UT Jan 18 to } & \text { 0200 UT Jan 21 to } \\ \text { 1300 UT Feb 4, 1989 } & 1200 \text { UT Feb 2,1991 } & \text { 1900 UT Feb 5, 1991 }\end{array}$

\begin{tabular}{|c|c|c|c|c|c|}
\hline $\begin{array}{l}\text { Depth, } \\
\text { m }\end{array}$ & $\begin{array}{c}\text { Angle, } \\
\text { deg }\end{array}$ & $\begin{array}{l}\text { Depth. } \\
\text { m }\end{array}$ & $\begin{array}{c}\text { Angle. } \\
\text { deg }\end{array}$ & $\begin{array}{l}\text { Depth. } \\
\text { m }\end{array}$ & $\begin{array}{c}\text { Angle, } \\
\text { deg. }\end{array}$ \\
\hline
\end{tabular}

\begin{tabular}{|c|c|c|c|c|c|}
\hline Surface & $217 \pm 47$ & Surface & $207 \pm 14$ & Surface & $81 \pm 49$ \\
\hline 12.6 & $242 \pm 53$ & 13.8 & $211 \pm 26$ & 16.4 & $31 \pm 32$ \\
\hline 20.8 & $245 \pm 63$ & 22.0 & $209 \pm 31$ & 24.6 & $31 \pm 21$ \\
\hline 28.9 & $243 \pm 66$ & 30.2 & $206 \pm 29$ & 32.8 & $35 \pm 26$ \\
\hline 37.1 & $243 \pm 62$ & 38.3 & $205 \pm 29$ & 40.9 & $37 \pm 24$ \\
\hline 45.2 & $243 \pm 62$ & 46.5 & $201 \pm 28$ & 49.1 & $36 \pm 18$ \\
\hline 53.4 & $244 \pm 60$ & 54.6 & $199 \pm 26$ & 57.2 & $34 \pm 20$ \\
\hline 61.6 & $244 \pm 64$ & 62.8 & $200 \pm 27$ & 65.4 & $34 \pm 18$ \\
\hline 69.7 & $239 \pm 70$ & 71.0 & $200 \pm 27$ & 73.6 & $33 \pm 18$ \\
\hline Ship & $230 \pm 95$ & Ship & $191 \pm 52$ & Ship & $161 \pm 42$ \\
\hline
\end{tabular}

The $E S(\mathrm{~dB})$ calculated in this way showed only minor differences from what would have been obtained by using a constant scale factor to convert the AGC; effective scale factors for M1 and M2, computed from the regression of AGC and $E S(\mathrm{~dB})$, were 0.47 and 0.46 , respectively. A transducer face on M3 had been replaced subsequent to calibration; therefore a value of 0.46 was assumed. Use of these constant scale factors gave estimates of $E S(\mathrm{~dB})$ with standard errors less than $1 \mathrm{~dB}$.

It is important to note that absolute calibration of power into the water was not known; therefore values of $E S(\mathrm{~dB})$ were defined relative to an arbitrary level, and intercomparisons between instruments would be inappropriate.

No correction for propagation effects have been made, but these will be minimal as vertical excursions experienced by the moorings were minor. Additionally, the presented wind speeds have been corrected to $10 \mathrm{~m}$, assuming a logarithmic profile, with a roughness length of $z_{0}=2 * 10^{-4} \mathrm{~m}$.

At M2 (Figures $2 b$ and $2 c$ ) and M3 (Figures $2 d$ and 2e) fluctuations in the time series of $E S(\mathrm{~dB})$ closely imitated those of wind speed on time scales as short as an hour. Considering first $\mathrm{M} 2$, a regression of the hourly averages of $E S(\mathrm{~dB})$ against $\log , U$ (Figure $3 a$ ) prior to the failure of the meteorological buoy yields

$$
\log , U=-1.31( \pm 0.07)+0.029( \pm 0.001) E S(\mathrm{~dB})
$$

with a correlation coefficient $r$ of 0.96 (99\% significance level is 0.76). Similarly for the longer records at M3 (Figure $3 b$ ),

$$
\log , U=-1.24( \pm 0.09)+0.029( \pm 0.001) E S(\mathrm{~dB})
$$

where $r=0.71$ (99\% sign cance level is 0.37). Here, the considerable scatter at $U<1.0 \mathrm{~m} \mathrm{~s}^{-1}$ has been excluded. At low velocities, near-surface bubble concentrations are reduced [Wu, 1988], and it may be that surface wave patterns play a stronger role in regulating the intensity of the specularly reflected surface backscatter. In addition, buoy motion may at times induce a degree of "pumping" of the anemometer, producing anomalies at speeds close to the threshold.

Similar analysis at M1 was precluded by the loss of the meteorological buoy. A less satisfactory comparison with the
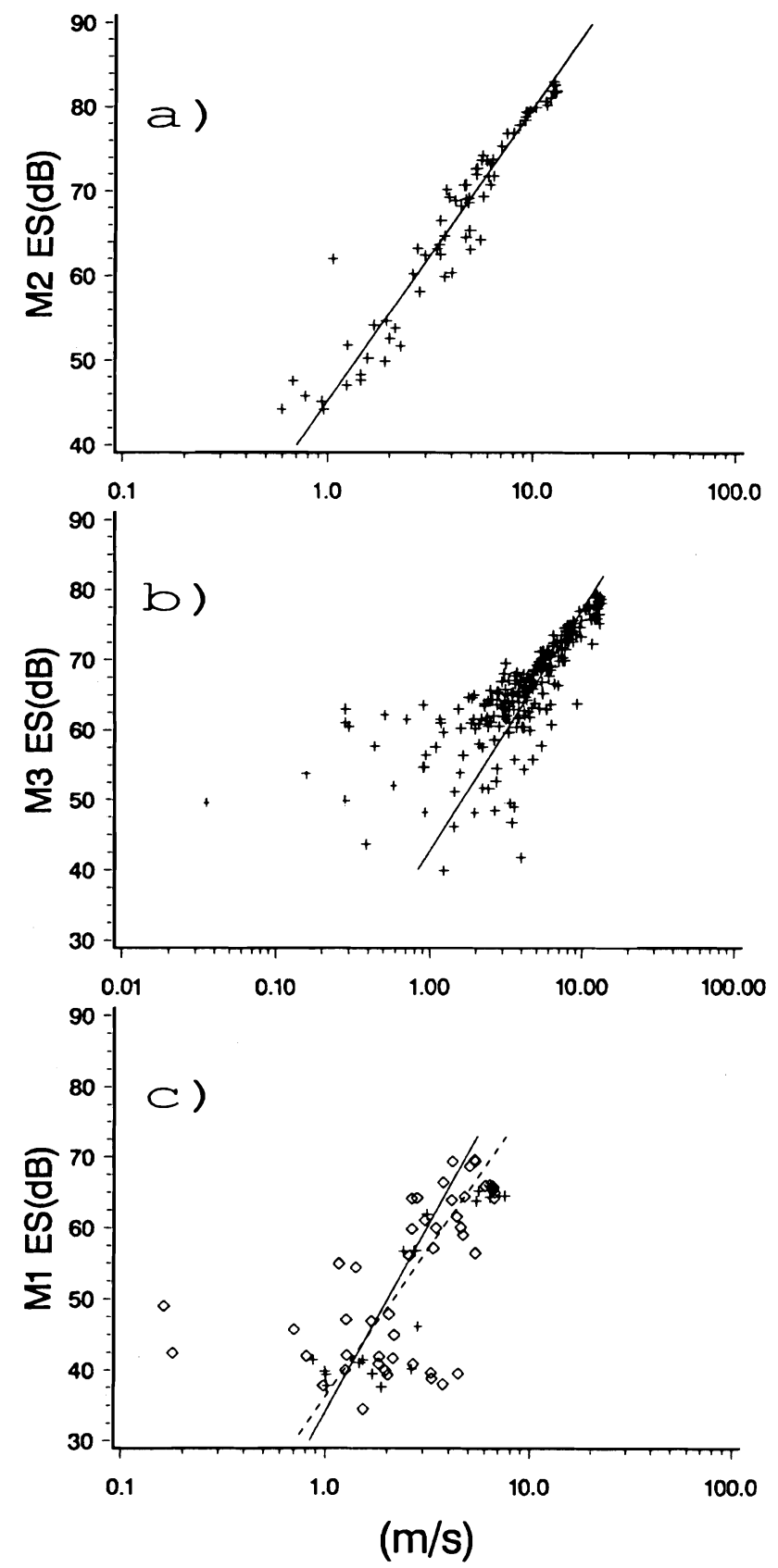

Fig. 3. Hourly values of wind speed (abscissae) versus surface echo strength (ES(dB)) (ondinates). (a) M2 with the regression line of equation (2). (b) M3 with the regression line of equation (3) (speeds $>1.0 \mathrm{~m} \mathrm{~s}^{-1}$ ). (c) Wecoma winds within $50 \mathrm{~km}$ of M3 represented by both symbols and the solid line of equation (4), with the data within $20 \mathrm{~km}$ given by crosses and the dashed line of equation (5).

winds recorded on board the RV Wecoma $\left(U_{w}\right)$ can be made. An inspection of the records from M2 and M3 (Figures $2 b-2 e$ ), separated by $112 \mathrm{~km}$, reveals that although the main features are common, there are marked differences. Approaches to mooring sites were spasmodic, rarely for more than 12 hours and separated by 2 to 5 days. The decorrelation time [Davis, 1976] for the ES(dB) signal was of order 1 day; therefore each approach can reasonably be regarded as 1 degree of freedom. Regressions applied to ship data within $50 \mathrm{~km}$ and $20 \mathrm{~km}$ of M1, equations (4) and (5), respectively, yield

$$
\log , U_{w}=-0.648( \pm 0.143)+0.019( \pm 0.003) E S(\mathrm{~dB})
$$


$\boldsymbol{r}=\mathbf{0 . 6 6}(\mathbf{9 5 \%}$ significance level is $\mathbf{0 . 6 7})$ and

$$
\log _{10} U_{w}=-0.869( \pm 0.158)+0.024( \pm 0.003) E S(\mathrm{~dB})
$$

$\boldsymbol{r}=\mathbf{0 . 8 8}(\mathbf{9 9 \%}$ significance level is $\mathbf{0 . 8 8})$. Levels of competence are reduced in comparison with equations (2) and (3), particularly at 50-km separation, emphasizing the desirability of making comparisons as close to the moorings as possible. In addition, the Wecoma was unable to work in the vicinity of the mooring during strong winds, therefore comparisons are further hampered by the restricted range of wind speeds (0.0-7.4 $\left.\mathrm{m} \mathrm{s}^{-1}\right)$. Further, during periods of light winds the accuracy of velocities, derived by removal of the ship speed over the ground, becomes less certain.

\section{WIND DIRECTION}

Here, we have adopted the oceanographic convention that the angles, measured with respect to true north, denote the direction of travel, i.e., toward which air parcels move.

Comparisons of the near-surface ADCP directional information with that from the buoys were hampered by the loss of M1 and the malfunction of the vane at $\mathbf{M 3}$; therefore $\mathbf{M} 2$ provided the sole moored vector-wind data set, of duration $\mathbf{7 2}$ hours. Again, hourly averages are considered, which in the case of the buoys were derived from 6 min spot readings. Consequently, at low speeds contamination of the data by wave-induced buoy motion may occur. Vector wind information was recorded on board Wecoma every minute.

Time series of wind direction recorded at M2 and aboard Wecoma are presented in Figure 4, accompanied by the surface directional information derived from the ADCPs. Excluding M3, directions were predominantly between southwest and southeast,
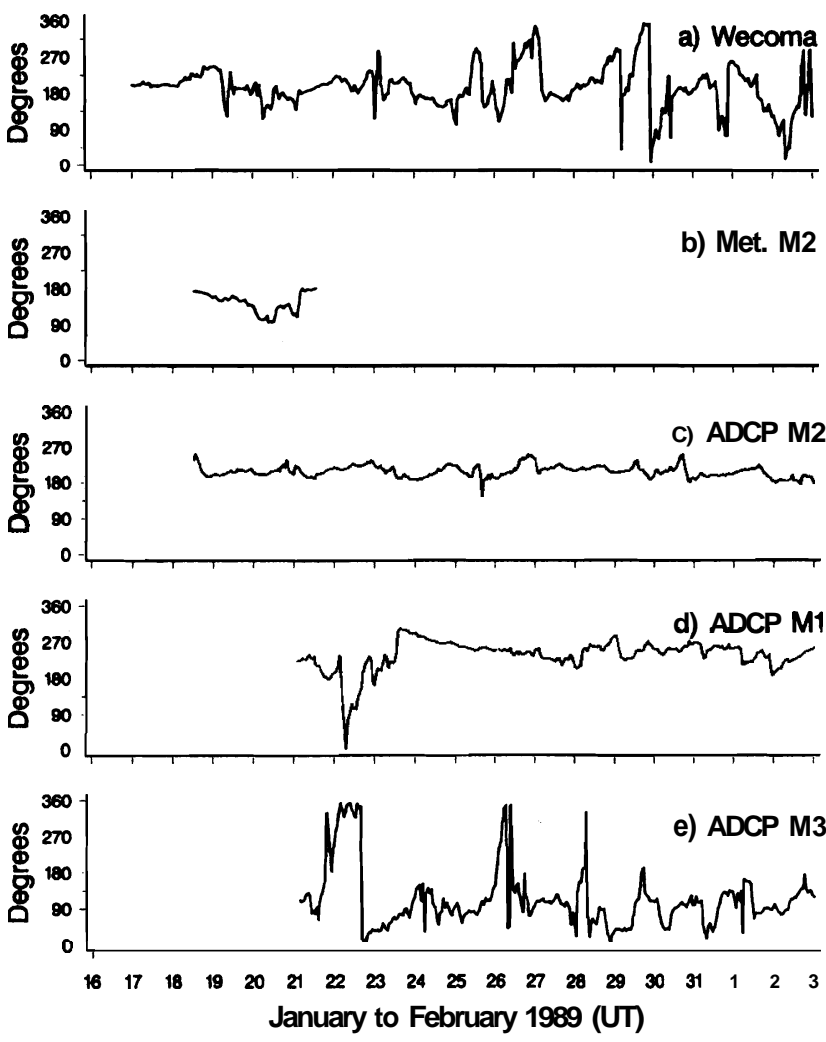

Fig. 4. Direction time series, following the convention that the angle is relative to true north and toward the direction of flow. (a)Wecoma, (b) meteorological buoy M2, (c) near-surface $\mathrm{ADCP}$ at M2, (d) near-surface $\mathrm{ADCP}$ at MI, and (e) near-surface $\mathrm{ADCP}$ at $\mathrm{M3}$. consistent with the nature of the atmospheric forcing during the Norther season. Regressions between the curtailed buoy record at M2 and the ADCP, or for ship board data within $50 \mathrm{~km}$ and the ADCPs at M1 and M2 are of little value, as in each case, directions were generally confined within a sector of less than $90^{\circ}$. The mean directions from the $\mathbf{M} 2$ buoy record and the ADCP during the same period were $138 \pm \mathbf{2 6}$ " and $206 \pm 8^{\circ}$, respectively. This difference of almost 70" might be thought attributable to the predominance of low wind speeds $\left(<5 \mathrm{~m} \mathrm{~s}^{-1}\right)$ in the record. Mean wind directions calculated for Wecoma data within $50 \mathrm{~km}$ of the ADCP moorings gave better results. At M1, the mean ship wind direction of $230 \pm 95^{\circ}$ agreed well with the mean direction of 227 $\pm 56^{\prime \prime}$ indicated by the ADCP; at M2 the ship mean was $191 \pm 52^{\circ}$ compared with the ADCP mean of $207 \pm 19^{\circ}$.

If it were not for the record at $\mathrm{M3}$ (Figure 4e), which indicates an eastward wind, it might reasonably be argued, as postulated by Schon [1989], that the near-surface ADCP directional information provides an adequate measure of wind direction. At $\mathbf{M 3}$ comparisons were limited to those with the Wecoma data. When within $50 \mathrm{~km}$ of the mooring the mean wind direction was $161 \pm$ $42^{\prime \prime}$ in contrast to $88 \pm 24^{\circ}$ at the ADCP. The ADCP value is consistent with that for the whole series of $81 \pm 49^{\circ}$. A comparison with the complete Wecoma record (mean $195 \pm 72^{\circ}$ ), covering the entire Gulf, would be inappropriate. The wind jet fans out after exiting the Chivela Pass, being southwestward to the west and southeastward to the east. Manifestly, there is an inconsistency between the results at $\mathbf{M 3}$ and those from M1 and M2, for which instrument malfunction seems an improbable explanation. Comparisons of direction and speed from independent measurements at the Aanderaa meters situated immediately below each ADCP and shipmounted ADCP data indicated excellent agreement.

\section{DISCUSSION}

Evidently,near-surface wind speed and the acoustic backscattered energy returned to ADCPs from the sea surface are strongly correlated. In the Gulf of Lions. Schott [1989], unable to record wind continuously at the ADCP moorings, was constrained to consider ship board data within a $\mathbf{1 0 0 - k m}$ radius and employ a $\mathbf{1 2 -}$ hour averaging period to smooth short-period inconsistencies. The close proximity of the instruments within the meteorological buoy/ADCP pails during the Tehuantepec experiment has shown that values correspond accurately on time scales of an hour.

Schott [1989] cited evidence that the echo amplitude signal might saturate at wind speeds exceeding $10 \mathrm{~m} \mathrm{~s}^{-1}$, a feature absent in the Tehuantepec data where maximum near-surface wind speeds at the moorings reached $15 \mathrm{~m} \mathrm{~s}^{-1}$. This disparity might be attributable to the use of 30" beam angles in Tehuantepec, whereas in the former effective angles of $\mathbf{2 0 "}$ and 24" were used. For beam angles relative to the vertical of between $\mathbf{0}^{\prime \prime}$ and approximately $15^{\prime \prime}$ the dominant backscattering process is taken to be specular from the normally inclined wave facets [Urick, 1975; Schott, 1989] and the slope factor of wind speed dependence is negative. At roughly $15^{\circ}$ there exists a crossover point to a positive dependence as Bragg scattering becomes increasingly dominant. In this region, changes in scattering strength become progressively less sensitive to increases in wind speed.

Upward looking ADCPs offer the potential to determine local surface wind stress without additional expensive and vulnerable surface instrumentation or recourse to ship board or land-based data that often fail to truly represent conditions at survey sites. Before the instruments can be regarded as replacements for wind buoys, questions remain to be answered. For instance; Are 
laboratory calibrations of transducer gains stable? How predictable are depth dependencies due to spreading, scattering, and absorption which will affect interpretation from separate deployments of an instrument? Is there a fetch dependence? Does the nature of the sea surface layer vary significantly with meteorological conditions?

Comparisons of near-surface ADCP directional information with ship board wind directions proved less satisfactory. An explanation may be found from an examination of the near-surface ADCP data (Table 1). During the observational period the direction of the flows in the surface layer at the western (M1) and central (M2) moorings was predominantly southwestward. At the eastern mooring (M3) there existed a persistent northeastward return flow toward the head of the Gulf. Thus, at M1 and M2, currents were essentially in the same direction as the wind, while a M3 they were in opposition to the dominant wind direction.

Considering only M1 and M2, one might conclude from the close agreement in the ship wind and surface bin directions that the near-surface ADCP directional information was representative of wind direction. Equally, it could be concluded that it was indicative of near-surface current direction. Extending consideration to $\mathrm{M} 3$, where the ADCP surface bin direction falls roughly midway (mean $81^{\prime}$ ) between the mean wind direction derived from the Wecoma when within $50 \mathrm{~km}$ of the mooring (mean $160^{\circ}$ ) and the current direction (mean - 32') (Table 1), it is reasonable to conclude that the near-surface signal is in fact some combination of the current and wind. Consideration of data when Wecoma and M3 are in closer proximity $(25 \mathrm{~km})$ produces little change, with means of $159^{\prime}$ and $\mathbf{8 7}^{\circ}$, respectively. Excluding periods of weak winds $\left(<3 \mathrm{~m} \mathrm{~s}^{-1}\right)$, when directions might be expected to be variable, yields the same results.

The ADCP time series is illustrated in (Figure 5), where it is
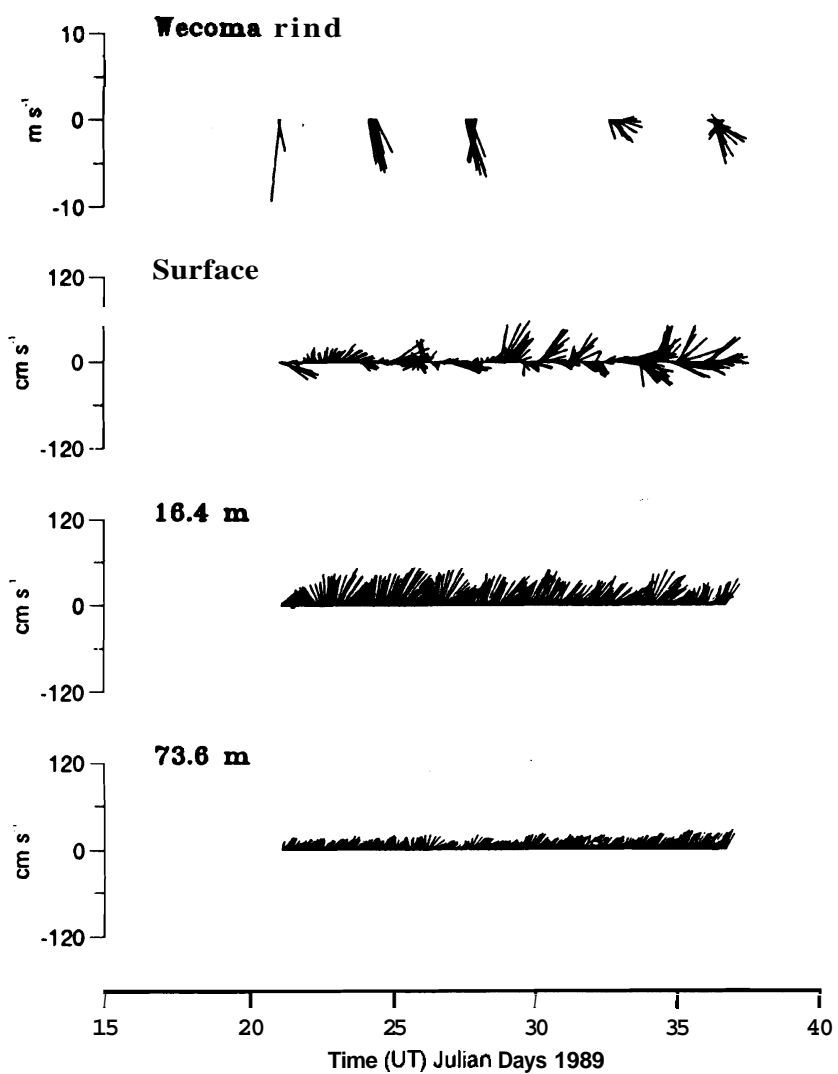

Fig. 5. Horizontal current vector time series at M3 with Weconia winds when within $50 \mathrm{~km}$ of the mooring. evident that current direction was simiiar throughout the upper layers and essentially opposed to Wecoma wind (separation < 50 $\mathrm{km}$ ) diction, while the surface bin direction varied between the two. This seems reasonable, as the Doppler shift measured at the $\mathrm{ADCP}$ is a power-averaged mean of those generated by advancing and retreating surface waves and the velocity of scatterers within the water column, the latter being additionally advected by the mean flow [Apeh 1987].

During the periods of consideration, in both the Gulfs of Lions [Schott, 1989] and Tehuantepec, circulation was primarily wind driven. The experiments differed in that in the latter, an ADCP (M3) was situated in a region forced indirectly where circulation persistently opposed the wind direction. Indeed, Schott [1989] discarded several periods of strong barotropic flows extending into the surface zone when currents clearly opposed the wind direction. It may be that under a more diverse current regime his findings might have differed.

In conclusion, the present data set shows that the near-surface backscattered energy recorded at the ADCP provides a good measure of wind speed, on time scales of an hour with apparently no saturation of the $E S(\mathrm{~dB})$ signal at higher wind speeds. The directional information from the near-surface Doppler data agreed with the observed wind direction only where the underlying current (at $20 \mathrm{~m}$ ) was in nearly the same direction as the wind. At the site where the directions of the underlying current and wind differed by almost $120^{\circ}$, the near-surface Doppler data indicaled an intermediate direction. This casts doubt on the ability of the Doppler measurements to provide reliable estimates of the wind direction.

Acknowledgements. UCNW funding was provided by the Natural Environmental Research Council (grant GR3/6719) and for OSU by the Office of Naval Research (contract N00014-87-K-0009; grant N00014-90J-1177). Thanks are also due to all those who contributed to the Tehuantepec project.

\section{REFERENCES}

Apel, J.R., Principles of Ocean Plyysics, Int. Geophys. Ser., vol. 38, 534 pp.. Academic. San Diego, Cali.. 1987.

Davis, R.E. Predictability of sea surface temperature and sea level pressure anomalies over the North Pacific Ocean, J. Plrys. Oceanogr., 6, 249-266, 1976.

Derecki, J.A.. and F.H. Quinn, Use of current meters for continuous measurements of flows in large rives, Water Resour. Res.. 23. 1751-1756, 1987.

Flagg, C.N. and S.L. Smith, On the use of the acoustic Doppler current profiler to measure zooplankton abundance. Deep Sea Res., 36, 455-474, 1989.

Heywood, KJ.. S. Scrope-Howe, and ED. Barton. Estimation of zooplankton abundance from shipborne ADCP backscatter, Deep Sea Res.. 38. 677-691, 1991.

Hurd, W.E, Northers of the Gulf of Tehuantepec. Mon. Weather Rev.. 57, 192-194, 1929.

Johns, W.E. Near-surface current measurementsin the Gulf Stream using an upward-looking acoustic Doppler current profiler, J. Atmos. Oceanic Technol, 5, 602-613. 1988.

Jones. W.L, L.C. Schroeder, D.H. Boggs, EM. Bracalente. R.A. Brown, G.J. Dome. WJ. Pierson, and FJ. Wentz, The Seasat A satellite scatterometer: The geophysical evaluation of remotely sensed wind vectors over the ocean. J. Geophys. Res., 87, 3297-3317, 1982.

RD Instruments, Acoustic Doppler Current Profilers principles of operation: A practical primer. 36 pp.. San Diego, Cali., 1989.

Roden, G.I., On the wind driven circulation in the Gulf of Tehuantepec and its effect upon surface temperatures. Geofis. Int., 1, 55-80, 1961.

Schott. F., Measuring winds from underneath the ocean surface by upward looking acoustic Doppler current profilers, J. Geophys. Res., 94, 8313-8321, 1989. 
Schott, F, and W. Johns. Half-year Long measurements with a buoymounted Acoustic Doppler Current Profiler in the Somali Current. J. Geophys. Res., 92, 5169-5176, 1987.

Schott, F. and K.D. Leaman, Observations with moored acoustic Doppler current profilers in the convection regime of the Gulf of Lions, J. Phys. Oceanogr., 21, 558-574, 1991.

Trasvina, A Offshore wind forcing in a coastal ocean: observations and modeling of the Gulf of Tehuantepec, Mexico, Ph.D. Thesis. 88 pp.. University of Wales. 1991.

Urick, RJ.. Principles of Underwater Sound. 2nd ed., 384 pp.. McGrawHill, New York, 1975.

Wu. J.. Bubbles in the near-surface ocean: A general description. $\mathbf{J}$. Geophys. Res., 93, 587-590, 1988.
E.D. Barton and H.S. Velez, School of Ocean Sciences. University of Wales. Bangor, Menai Bridge. Gwynedd, LL59 5EY, Wales.

J. Brown, M.A.F.F. Fisheries Laboratory. Lowestoft, Suffolk NR33 OHT, England.

P.M. Kosro and R L Smith. College of Oceanography. Oregon State University, Corvallis, Oregon 97331.

A. Trasvina, Centro de Investigacion Cientifica y Educacion Superior de Ensenada, Ensenada, British Colombia. Mexico.

(Received January 27. 1992; accepted March 30. 1992.) 